\title{
HISTORIA POLÍTICA Y PROFECÍA: ROMA Y LOS GRANDES IMPERIOS ANTIGUOS A LA LUZ DE LAS PREDICCIONES DEL PROFETA DANIEL
}

\author{
POR
}

\author{
FLORENCIO HUBEÑÁK
}

Universidad Católica Argentina (Buenos Aires)

\section{Resumen}

El autor examina el largo conjunto de interpretaciones a que dio lugar, en la Antigüedad, la profecía de Daniel basada en un sueño de Nabuconodosor y referida al nacimiento, apogeo y crisis del futuro Imperio romano.

\begin{abstract}
History, politics and prophecy: Rome and the great ancient empires in Daniel prophet's predictions

Here is an examination of the whole of ancient historical interpretations of Daniel's prophecy about Nabuconodosor's dream and the birth, cenit and final crisis of the Roman empire.
\end{abstract}

Uno de los primeros problemas de los historiadores formados en las escuelas positivistas es, como ya señaláramos en otra oportunidad', trabajar con temas ajenos a la historiografía tradicional, manejándose con fuentes literarias, religiosas u otras.

1 Vease nuestro: "Terra et Urbs: la búsqueda de la mentalidad del ciudadano de la Roma republicana", Res Gesta, 22, (1987), 127 ss.

Imagen y representación de los otros Hispania Sacra 48 (1996) 
Estos temas relativamente novedosos en esa historiografía, pese a su dificultad, no deben ser ajenos a los investigadores ya que cubren un amplio espectro de la realidad histórica que no merece ser descuidado. Estos aspectos se acrecientan de manera significativa cuando nos referimos a cuestiones vinculadas a la historia antigua o medieval; periodos en los cuales el hombre era mucho menos racionalista y en que las creencias proféticas influían considerablemente en la vida pública y privada.

Una de las múltiples posibilidades de enfocar algunos de los temas de estas características -que nosotros consideramos básicos para el conocimiento del mundo antiguo- es la profecía, hasta ahora bastante descuidada por los historiadores. Sobre ella escribió Arnoldo Momigliano que "es ciertamente una palabra muy vaga, pero antes de efectuar cualquier precisión es necesario tener en mente el hecho elemental que la profecía es especialmente una combinación de tentativas genuinas de adivinar el futuro con juicios y definiciones de acontecimientos pasados"2 . .

Entre el amplísimo espectro de temas referidos a estas cuestiomes hemos seleccionado, por la amplitud de campos que abarca, la profecía de Daniel, intentando aportar aquí solamente un panorama somero del estado de las discusiones.

El texto que nos interesa expone las interpretaciones que realiza el profeta de un sueño que tuvo el monarca babilonio Nabuconodosor. Daniel escribe: "Oh rey, los pensamientos que agitaban tu mente en el lecho se referían a lo que ha de suceder en el futuro, y el que revela los misterios te ha dado a conocer lo que sucederá. A mí, sin que yo posea más sabiduria que cualquier otro ser viviente, se me ha revelado este misterio con el solo fin de manifestar al rey su interpretación y de que tú conozcas los pensamientos de tu corazón. Tú, oh rey, has tenido esta visión: una estatua, enorme estatua, de extraordinario brillo, de aspecto terrible, se levantaba ante tí. La cabeza de esta estatua era de oro puro, su pecho y sus brazos de plata, su vientre y sus lomos de bronce, sus piernas de hierro y parte de arcilla. Tú estabas mirando, cuando de pronto una piedra se desprendió, sin intervención de mano alguna, vino a dar a la estatua en sus pies de hierro y arcilla, y los pulverizó. Entonces quedó pulverizado todo a la vez: el hierro, la arcilla, el bronce, la plata y el oro, quedaron como el tamo de la era en verano, y el viento se lo llevó sin dejar rastro. Y la piedra que había golpeado la estatua se convirtió en un gran monte que llenó toda la tierra. Tal fue el sueño; ahora diremos ante el rey su interpretación. Tú, oh rey, rey de reyes, a quien el Dios del cielo ha dado reino, imperio, poder y

2 Momigliano, A.." Dalla Sibilla pagana alla Sibilla cristiana: Profezia como storia della retigione, Annali di Pisa, XVIL (1987), 407.

Imagen y representación de los otros Hispania Sacra 48 (1996) 
gloria -los hijos de los hombres, las bestias del campo, los pájaros del cielo, donde quiera que habite, los ha dejado en tus manos y te ha hecho soberano de ellos--, tú eres la cabeza de oro. Después de tí surgirá otro reino, inferior a tí, y luego un tercer reino, de bronce, que dominará la tierra entera. Y habrá un cuarto reino, duro como el hierro, como él hierro que todo lo pulveriza y machaca, como el hierro que aplasta, así el pulverizará y aplastará a todos los otros. Y lo que has visto, los pies y los dedos, parte de arcilla y parte de hierro, es un reino que estara dividido; tendrá la solidez del hierro, según has visto el hierro mezclado con la masa de arcilla. Los dedos de los pies, parte de hierro y parte de arcilla, es que el reino será en parte fuerte y en parte frágil. Y lo que has visto: el hierro mezclado con la masa de arcilla, es que se mezclarán el uno al otro, de la misma manera que el hierro no se mezcla con la arcilla. En tiempo de estos reyes, el Dios del cielo hará surgir un reino que jamás será destruido, y este reino no pasará a otro pueblo. Pulverizará y aniquilará a todos estos reinos, y él subsistira eternamente: tal como has visto desprenderse del monte, sin intervención de mano humana, la piedra que redujo a polvo el hierro, el bronce, la arcilla, la plata y el oro. El Dios grande ha manifestado al rey lo que ha de suceder. El sueño es verdadero y su interpretación digna de confianza (II-29/46).

El mismo Daniel completa este texto, que ha dado lugar a tanta literatura, con otra profecía. En el capítulo VII del mismo libro agrega el sueño de las cuatro bestias. Allí relata (1/16) la visión para pasar más adelante a explicarla en estos términos: "Estas cuatro grandes bestias son cuatro reyes que surgiran de la tierra. Los que han de recibir el reino son los santos del Altísimo, que poseerán el reino eternamente por los siglos de los siglos. Después quise saber la verdad sobre la cuarta bestia, que era diferente de las otras, extraordinariamente terrible, con dientes de hierro y uñas de bronce, que comía, trituraba y pisoteaba con sus patas lo sobrante; y acerca de los diez cuernos que había en su cabeza, y del otro cuerno que había despuntado, ante el cual cayeron los tres primeros; y de este cuerno que tenía ojos y una boca que decía grandes cosas, y cuyo aspecto era mayor que el de los otros. Y lo que había visto también, que este cuerno hacía la guerra a los santos y los iba subyugando, hasta que vino el Anciano a hacer justicia a los santos del Altísimo, y llegó el tiempo en que los santos poseyeron el reino. El hablo así: Y los diez cuernos: de este reino saldrán diez reyes, y otro saldrá después de ellos; será diferente de los primeros y derribará a tres reyes; proferirá palabras contra el Altísimo y pondrá a prueba a los santos del Altísimo. Tratará de cambiar los tiempos y la ley, y los santos serán entregados en sus manos por un tiempo y por tiempos y por medio tiempo. Pero tendrá lugar el juicio, y el imperio se le quitará, para ser destruido y aniquilado totalmente. $Y$ el reino y el imperio y la grandeza de los reinos bajo los cielos todos serán dados al pueblo de los santos del Altísi- 
mo. Reino eterno es su reino, y todos los imperios lo servirán y le obedecerán" (VII-17/27).

El texto que acabamos de leer nos trae una serie de interrogantes vinculados con la temática que nos ocupa. En primer lugar resultará de interés situar al autor de la profecíay el tiempo en que fue escrita la misma; luego trataremos de abordar la cuestion de las fuentes en las que pudo o pudieron basarse él o los autores de la profecía (nuestro Daniel) para pasar a ocuparnos de la interpretación que de la misma realizaron distintos historiadores en los tiempos antiguos, con especial referencia al papel que en la misma le cupo a Roma.

Con referencia a la cuestión de la autoría se plantean varias dificultades. La tradición judía considera como autor de todo el libro a un profeta Dani”el ("Dios es mi juez"), de la tribu de Sedecías- según afirma el historiador Flavio Josefo ${ }^{3}$, quien en el 605 a C. había sido llevado prisionero a Babilonia en tiempos del rey Nabuconodosor y altí habría realizado las profecías que le conocemos. Esta tesis ha sido muy discutida por los modernos estudios exegeticos que suelen considerar que las dos profecías que hemos citado pertenecen a épocas y autores distintos.

Así el libro II -el primero de los textos- habría sido redactado en tiempos muy antiguos -quizás no más allá del siglo III a C.- en parte en hebreo y otra en arame $0^{4}$, mientras que, con mayor exactitud, se sostiene que la segunda

\footnotetext{
3 "Algunos autores se niegan a admitir la autenticidad daniélica integral, pero no se resignan a datar el conjunto de la obra en el período macabeo. J. A. MONTGOMERY atribuye a un autor más antiguo ( Daniel o algún desconocido) los capítulos históricos (1-6) y a un escritor de la época de Antíoco Epífanes los oraculos proféticos (cap. 7-2). Otros (Buumgartner, Holscher Halłer) consienten en reunic el capítulo 7 con los seis primeros capítulos y datan esta fracción de la obra en los siglos III y IV. Otros (Riessler) hacen a Daniel autor de la sección profética, pero eștiman que los relatos históricos son de fecha más reciente. Varjos (Nikel, Gottsberg, Lagrangc) prefieren dejar en la indeterminación los elementos que un autor del siglo III o Il utilizaría para componer la obra tal como la conocemos actualmente, $\mathrm{o}$ incluso (Junker) restringen las adiciones del autor macabeo a las visiones de los capítulos 10-12" (RoberT, A. y FEulLet, A.: Introducción a la Biblia, Madrid, Herder, 1967 t.I, p. 638).

4 "Esta diversidad linguística plantea un problema no fácil de resolver, ya que no se ve la razón de por qué la parte histórica -homogénea por el contenido- está escrita en hebreo y en arameo, y lo mismo, por qué el c. 7, de contenido visionario y muy ligado al c. 8 está en arameo, mientras éste está en hebreo, y por qué el c. 1 está en dos lenguas. Se han propuesto diversas soluciones, pero ninguna es totalmente convincente. Unos suponen que primitivamente fue escrito todo en arameo y que después, para ocultar al vulgo el contenido misterioso de los capítulos "vișionarios" se los tradujo at hebreo, lengua accesible sólo a los eruditos e iniciados. Pero entonces queda el misterio de por qué el c. 7, de contenido "visionario", está en lengua vulgar aramea. Y, a! mismo tiempo, por qué el c. l, de contenido histórico, está en hebreo, y lo mismo los v. i y 2a del c. 2. Otros proponen la hipótesis contraria: originariamente habría sido escrito todo el libro (protocanónico) en hebreo; después se tradujo parte al arameo, dejando en hebreo la parte "visionaria"... apocalíptica y el c. 1 para que así 
profecía -el capítulo VII-, escrito en arameo, tuvo por autor a un judío del siglo II a C. Con más precisión aún los investigadores afirman que éste fue redactado indudablemente entre el 168 a C. -fecha de la profanación del templo de Jerusalén por el seléucida Antíoco IV- y el 165 a C., en que fuera nuevamente consagrado por Judas Macabeo ${ }^{5}$. Esto permite conjeturar que el redactor final -un judío ortodoxo preocupado por las persecuciones del monarca seléucida- se dedicó a compilar distintos textos "daniélicos" que circulaban en la Palestina helenizada. Es interesante remarcar -como bien señala Momigliano ${ }^{6}$ - que "parece obvio, sin embargo, que el autor o los autores que redactaron lo que ahora son los capítulos 7 al 12 del libro de Daniel conocían bien la primera parte. De hecho, hay señales de que el Libro de Daniel, aún componiéndose de elementos heterogéneos, lo recopiló con conspicua meticulosidad un "editor" al que le interesaba producir impresión de coherencia e incluso de armonia estilística".

Una de las primeras cuestiones que interesa analizar en el tema que nos ocupa consiste en intentar rastrear las fuentes en que se basó el autor de ambas profecías.

Como bien señala Evola?, "en todos los testimonios antiguos de la humanidad se puede encontrar siempre, de una u otra forma, la idea de un regreso, de una caída...", concepto vinculado a una cosmovisión urganicista y "cuaternaria" que se completa con la creencia en una regeneración (renacimiento)-, comúnmente conocido -a partir de Virgilio y Horacio- como "mito de la edad de oro".

Cabe recordar que en las más antiguas creencias tradicionales el número cuatro está directamente relacionado con las partes del día, con las estaciones del año, con las fases de la luna y más directamente con la vida en general, incluyendo las cuatro edades de ésta (infancia, adolescencia, madurez y vejez asumiendo así un carácter religioso.

tuviera más fácil acceso al canon judaíco (profesores de Salamanca, edit. M. GARCía CORDERo): Biblia Comentada, JI: Libros proféticos, Madrid, B.A.C., 1967, p. 984).

5 Momigliano precisa la fecha de redacción entre los últimos meses del I64 a C. y los primeros meses del 163 al afirmar que el autor desconoce aún la muerte de Antíoco IV ocurrida aśrededor de noviembre del 164 y la restauración del culto en Jerusalén que tuvo lugar aproximadamente al mismo tiempo. (en Daniel y la sucesión griega de los imperios, en La historiografía griega, Madrid, Crítica, 1984, p. 256). Ginsberg, en cambio, asegura que los textos fueron compuestos antes de la profanación del templo o al inicio de la persecución del 167 a C. (en Studies in Daniel, N. York, 1948, II cit. DELCOR, M.: Studi sull' apocalittica, Brescia, Palideia, 1987, p.135).

6 MOMIGLIANO, A.: "Los orígenes de la historia universal", en la historiografía griega, Madrid, Crítica, 1984, p. 282.

7 EvolA, J.: Rivolta contra il mondo moderno, Roma, Mediterranée, 1969, p. 221. 
Al buscar la versión más antigua de este "mito de las cuatro edades" podemos presumir que el mismo tiene un antiquísimo origen indoeuropeo que encontramos en las creencias de la India. Los pensadores indios sostienen la división en períodos de "cuatro edades", a las que denominan Krita-yuga o Satya-yuga (presumiblemente de shatur=cuatro), Treta-yuga ( de tri=tres), Dwapara-yuga (de $d v i=$ dos) y Kali- yuga (de $e k a=$ uno) que concluyen en una disolución final (pralaya) que permite la reapertura de un nuevo ciclo8.

Esta misma temática la reencontramos en la teología persa del Avesta, básicamente en dos textos como el Sudkarnask (conservado en el Dinkart. IX-8) y el Vohumán-yast (Y-3). Según el primero de estos textos referidos a los cuatro períodos del milenio de Zaratustra, primero hubo una edad de oro, en la que Ahura Mazda enseñó la religión; en segundo lugar la de plata, en que Vistasp (nuestro rey Histapes) recibió la religión de Zaratustra; en la tercera, de acero, en que nació Adurpad, hijo de Maraspend, el revelador del derecho; y una cuarta, de bronce mezclado, en que apareció "mucha propaganda sobre la autoridad de los apóstatas y otros malvados"9.

"El segundo texto preserva mejor la narración original y su simbolismo: Zaratustra interrogó a A hura Mazda sobre la inmortalidad...; éste narró a Zaratustra su visión, consistente en el bronce de un árbol que tenía cuatro ramas o brazos de metal: de oro, plata, acero e hierro mezclado respectivamente. El tronco era el material con que Ahura Mazda creara; los cuatro brazos son los cuatro períodos futuros: el de oro es aquel en que tras haber escuchado la prédica el rey Vistasp aceptó la religión..., el de plata es el reinado de Artashkir y el de acero el de Khvasruy (nuestro Kosroes), hijo de Kawat, de inmortal memoria; y el de hierro mezclado pertenece a la soberanía del mal"10.

Pero sin lugar a dudas la versión más conocida del "mito de las cuatro edades" identificadas con los metales se encuentran en Los Trabajos y los Días del poeta griego Hesíodo. Narra éste en el libro I: "Cuando al mismo tiempo nacieron los dioses y los hombres mortales; primero los Inmortales que tienen moradas olímpicas crearon la edad de oro... Después, los habitantes de las moradas olímpicas suscitaron una segunda generación muy inferior, la edad de plata, que no era semejante a la edad de oro ni en el cuerpo ni en la inteligencia... Y el padre Zeus suscitó una tercera raza de hombres parlantes, la edad de bronce, muy distinta a la edad de plata... Después que la tierra hubo escondido esta generación, Zeus Crónida suscitó otra raza divina de héroes más justos y mejores que fueron Illamados semidioses en toda la tierra por la generación

\footnotetext{
* Eliade, Mircea: El mito del eterno retorno, Madrid, Alianza, 1979, espec. p. $106 / 7$.

- FLUSSER, DAVID:"The fot Orienial Studies" ([972), 166.

in Idem, p. 166.

Jmagen y representación de los otros Hispania Sacra 48 (1996)
} 
presente... ¡Oh si no viviera yo en esta generación quinta de hombres, o más bien, si hubiera muerto antes o nacido después! porque ahora es la edad del hierro. Los hombres no cesarán de estar abrumados de trabajos y miserias durante el día, ni de ser corrompidos durante la noche, y los dioses les prodigarán amargas inquietudes. Entretanto los bienes se mezclarán con los males. Pero Zeus destruirá también esta generación de hombres cuando se les tornen blancos los cabellos"l].

Una vez transcritas las posibles fuentes de inspiración de Daniel -o del posible compilador que conocemos bajo ese nombre-- corresponde nos interroguemos sobre el uso de las mismas por parte de éste. La mayoría de los investigadores coinciden en afirmar que Daniel adoptó ciertas concepciones previas o vigentes y las trasladó al contexto de sus profecías, adaptando las teorías de los metales o de las cuatro edades a su objetivo de la lucha frente a las persecuciones seleúcidas, a la vez que planteaba -en el contexto apocalíptico de su época- las esperanzas mesiánicas judías. Como bien sintetiza Lucrezi, Daniel fue "bandera de la fiereza Yavhista y de la oposición al extranjero, verdadero y propio manifiesto político-religioso contra el tirano sirio (Antioco Epífanes) ${ }^{12}$.

La problemática y falta de coincidencia se plantea cuando tratamos de encontrar de cuál de las fuentes anteriormente citadas extrajo Daniel esta concepción. Algunos autores no vacilan en asegurar que la fuente es persa ${ }^{13} \circ$

II El mito de las cuatro edades de los metales, tradicionalmente identificado con la literatura greco-romana, reaparece en oiros autores romanos. Así Ovidio escribe: "Ln edad de oro fue creada en primer lugar, edad que sin autoridad y sin ley, por propia iniciativa, cultivaba la lealtad y el bien (...). Una vez que después da haber sido Saturno precipitado al Tártaro tenebroso, el mundo cstuvo sometido a Júpiter, llegó la generación de plata, peor que el oro pero más valiosa que el rubicundo bronce (...).Tras ésta apareció en tercer lugar la generación de bronce, más cruel de carácter y más inclinada a las armas salvajes, pero no por eso criminal. (...). La última es de duro hierro, de repente irtumpió toda clase de perversidades del más vil metal" (Metamorfosis, Y-69/150). Tampoco es ajeno el tema a la pluma de Horacio quien narra que “.. Júpiter reservó tales parajes a piadosas gentes, en la era en que el bronce fatal mancilló el oro. Siguió la edad del hierro más funesta. Salvarse de la cual pueden los buenos, con tal que en mí confen, su profeta" (Epodo XVI: Al pueblo romano). Y el tema tampoco es ajeno al historiador Dión Casio cuando, después de referirse a la muerte del emperador Marco Aurelio, dice que "la histolia pasó de un imperio de oro a uno de hierro, oxidado" (cit. MAZARINO, S.: El fin del mundo antiguo, Mexico, U.T.E.H.A., 1961, p. 29).

12 LUCReZI, FCo.: "Danielle, la Sibilla e I'Impero", en Da Ronta alla Terza Ronta. Nápoles, Edizione Scientifiche Italiane, 1986, p. 28.

13 Tal la antigua tesis de Eduard Meyer (Ursprung und Anfonge des Christentums, 11, 1921, p. 289) retomadn, en otros por F. CUMONT: "La fin du monde selon les mages occidentaux", Revte Hist.der Religions, 113 (1931). Swain, Joseph Ward ("The theory of the four monarchies opposition history under the Roman Empire", Classical Philology, XXXV, enero 1940, I) coincide con esta tesis, afirmando que el parecido con Hesíodo es "pura coincidencia" (p. 11). FLUSSER, D. "The four empires in the fouth sibyl and in the Book of Daniel". Israel Oriental Studies, 1972) acepta el origen 
babilónica ${ }^{14}$, mientras que otros se inclinan a defender la raíz helénica, especialmente hesiódical ${ }^{15}$, sin que por ello tampoco falte alguno que señale sus preferencias por Heródoto ${ }^{16}$. El orientalista Cumont, al inclinarse por la antigua tesis iránica de Eduard Meyer ${ }^{17}$, advierte que la diáspora judía se encontró -y enfrentó- con la similar persa y los mismos helenos estuvieron vinculados durante tiempos más o menos prolongados con los mazdeos de la Anatolia y en la Mesopotamia con los de Persépolis y Ecbatana ${ }^{18}$.

Por otra parte West ${ }^{19}-\mathrm{y}$ algunos otros- sugiere que muchos mitos orientales habrían penetrado en la Hélade durante el período micénico y fueron in-

persa, agregando que éstos ya vinculaban las distintas edades y metales con la sucesion de reyes dentro de un mismo imperio. Igualmente hace notar que "el zoroastrismo creín en una nueva creación escatológica, pero no en una renovación cíclica del mundo. Esıo fue aportado - señala- por los estoicos (cfr. Egloga $I V$ de Virgilio) con la aclaración que el gramático Servio, al glosar ja $I V$ Egloga virgiliana, refleja ideas persas" (p. 163 y 164). También se inclina a favor de este origen Baumgartner ('Zu de vier reichen von Daniel", Theologische Zeitschrif, 1, 1945, p. 17-22) quien sugiere que fue importada por colonos persas del Asia Menor. WINSTON, D. ("The Iranian Component in the Bible, Apocrypha and the Qumran", History of Religions, 5, 1966, p. 183-216) sostiene, en cambio, que fue llevada al Asia Menor por emigrances persas con anterioridad al reinado de Jerjes (I86/65 a. C. y quizás fuera utilizada como "arma publicitaria persa" ante los embates del helenismo. Cabe agregar como bien sintetiza J.M. ALONSO NÚNẼE ("Aemilius Sura", Latontus, XLVIII, I, p. 1 13-4)- que el origen oriental "es obvio" y que esta es la opinión de la mayoría de los historiadores. (Gabba, Ferrary, Trompf, Walbanck y Gruen).

14 Swain, Joseph Ward (op. cit., p. 9, nota 20) se inclina por un origen babilónico, basándose en investigaciones de A.K.GRAYSON (Babylonian Historical-Literary Texts. Toronto, 1975, p. 24/37) quien "descubrió una profecfó dinástica" con similitudes con el Libro de Daniel (cfr. MomiglaANo, A.: Los orígenes... cit. p. 285).

is Los opositores a la tesis persa anteriormente mencionada se basan fundamentalmente en que la fuente real, el Denkart -que tranșmite los textos más antiguos- es una enciclopedia de nueve libros, perteneciente al período pahlavi, datado alrededor de los siglos IX o X de nuestra era. La tesis hesiodica tiene un importante defensor en Momigliano (Daniel y la teoría..., p. 264), aunque en otra ocasión (Dalla Sibilla pagana...) haya afirmado que "secundariamente, aunque admita que haya algunas cosas comunes entre Hesíodo y Dariel, no encuentro en Hesíodo precisamente aquello que es lo más característico de Daniel: la solución apocalíptica (p. 422). "También la hallamos, aunque mitigada en Flusser (The four empires...) donde señala: "la secuencia de oro, plata, cobre e hierro en Daniei es clara: éstos son los metales de las cuatro edades de Hesíodo. El esquema en las fuentes persas omite el cobre e incorpora el acero, el cual es una clase de hierro; el cuarto período es de hierro mezclado. En Daniel es evidente la contaminación de ambos esquemas; en principio es vìsible el esquema conocido de Hesíodo, pero modificado" (p. 167).

16 Tal, por ejemplo, la advertencia de Momigliano cuando señala que hay diferencia esencial entre las cuatro razas de Hesíodo y las cuatro monarquías de Daniel. Me parece ahora muy probable que Daniel haya tomado las sucesiones de los imperios no de poetas griegos como Hesíodo, sino de historiadores griegos como Herodoto a quien era familiar la noción de monarquía mundial" (Dalla Sibilla pagana..., p. 423).

17 Véase nota 12.

18 CUMONT, F.: op. cit. p., 30.

19 WEST M.: Eariy Greek Philorophy and the Orient, Oxford, 1971, p. 205.

Imagen y representación de los otros Hispania Sacra 48 (1996) 
corporados por Hesíodo a la tradición griega, aún sin que el propio Hesíodo fuese consciente de ello.

Como podemos apreciar, la teoría "cuaternaria" de los metales existía en el sincrético ambiente judío helenizado de la época de los Macabeos y posiblemente aún con anterioridad por las sucesivas diásporas; $y$ así como sabemos que ningún griego ni romano utilizaron anteriormente la posible combinación de los metales con los reinos (imperios) sucesivos, surge que Daniel fue el primero en utilizarla ${ }^{20}$.

En otro aspecto, parece ser también que, en su intención religiosa de componer una haggadá para el pueblo perseguido, el inventor de "la contraposición de la noción del reino de Dios a los cuatro imperios" 21 como preparación a "un inminente reino de Dios"22, otorgaba a los perseguidos Macabeos una fuente de inspiración y ratificación de los acontecimientos que les tocaba vivir.

Creemos que esta concepción "cuaternaria" de los metales es de antiquisima raíz oriental, sin perjuicio de que Hesíodo haya entrado en contacto con ella a través de las cada vez más confirmadas relaciones entre Oriente y Occidente que hieren de muerte la tesis del "milagro griego", y haya cumplido un papel importante en su difusión.

Esta concepción fue amalgamada -parece que por Daniel- a la teoría grie$\mathrm{ga}^{23}$ de la sucesión de los reinos (translatio imperii). Este fue un tema que surgió necesariamente en los primeros historiadores hasta convertirse en un "topos" divisorio de épocas históricas por parte de sus continuadores. La mayoría de los historiadores coinciden en afirmar que el tema ya aparece definido en Herodoto -el padre de la historia- hacia fines del siglo V a. C. (I, 95) y que éste probablemente estructurara su información en sus viajes por el Cer-

21) Momiglano, A.: Daniel y la sticesiom... p. 259. De todos modos cotresponde hacer notar que en los textos persas anteriormente citados aparecen un orden de sucesión de reyes -no reinos- vinculada a la teoría de los metales, que podemos creer tuvo alguna influencia en Daniel.

2I Idem, p. 263.

22 Esta concepción apocalíptica es común en Daniel, quien imprimió a las creencias de su tiempo una forma original, "Lo apocalíptico inaugurado por el profeta Ezequiel (25-32; 37-39) hab́a tornado vuelos. Varios poemas del libro de Isaías (13-14; 24-27; 34-35) marcaban en este sentido una etapa importante. Ciertas partes de Henoc, del que recientemente se han descubierto fragmentos en Qumran, se presentan bastante corrientemente como contemporáneos de la época macabea: el apocalipsis de las semanas, la caída de los angeles, la asunción del héroe, serían anteriores al 165; el libro de los sueños, ligeramente posterior (hacia 161), proyecta vivas claridades sobre el de Daniel, Parece que se debe situar eл esta corriente al autor del libro canónico" (RoBERT, A. y FEUILLET, A.: Introducción a la Biblia, Madrid, Herder, 1967, t.l., p. 641).

2. Tal la opinión que sostiene MomiGLIANo (Los origenes..., p. 284-5). 
cano Oriente. Según nos refiere Diodoro de Sicilia ${ }^{24}$ fue Ctesias de Cnido, quien en su Historia de los persas en el siglo IV a.C., comienza su narración histórica con Asiria (el semilegendario rey Nino), para pasar luego a tratar de los medas y como sucesor de estos, de los persas. Según afirma D. Mendels ${ }^{25}$ "el topos de la decadencia y caída de los imperios del Este en la literatura griega y romana deriva de Ctesias".

Polibio de Megalopolis, que escribe en el siglo II, también emplea, aunque mitigadamente, esta teoría de sucesión al referirse a los imperios que le habían precedido $(\mathrm{Y}, 2)$, pero su aporte más importante, como veremos, consiste en la incorporación de Roma al esquema sucesorio, considerándolo el primer imperio universal (así su historia de Roma se llamará historia universal) y finalmente su atisbo de una Roma eterna ${ }^{26}$.

Pero el aspecto que nos interesa ahora, para seguir el hilo de nuestra exposición, pasa por las interpretaciones que el mundo greco-romano dio a las visiones de Daniel. Nadie duda que ambas profecías se complementan y explican mutuamente, como también existe coincidencia total en que el primer reino citado (la cabeza de oro y el león con alas de águila) se refiere al reinado de Nabuconodosor, como lo aclara el propio Daniel (II-38) ${ }^{27}$. El segundo reino (de pecho de plata y semejante a un oso) ha sido generalmente identificado con el imperio medo-persa, que sucedió al asirio-babilónico ${ }^{28}$. El tercer reino (vientre y lomos de bronce y un leopardo) ha sido señalado como el imperio de Alejandro Magno, al identificar al macho cabrío que abate al carnero (medo-persa) y "domina toda la tierra" (VIII-21) con el rey de Grecia. La tercera bestia "tiene cuatro alas sobre su dorso, para indicar la celeridad de águila en sus conquistas en las cuatro direcciones del viento. Es el imperio de

24 DIODORO: II, 1, 37.

25 "A five empires: a note on a propagandistic topos", American Journal of Philology, 102 , (198I), p. 334.

26 Polibio se nos aparece, junto con sus contemporíneos Ennios y Posidonio, como uno de los artifices del mito de la Roma eterna. Para este tema véase nuestro: "La primera Roma. El proceso de formación del mito de Roma", presentado en la XI Semana de Estudios Romanos organizada por la Universidad Católica de Valparaíso, 1989.

27 Como bien refiere M. DELCOR (Studi sull apocalittica, Brescia, Paidi, 1987, p. 142-3) el "Ieón alado" es característico de numerosas representaciones escultóricas de Babilonia y Asiria, indudable símbolo de la potencia del imperio babilónico. Delcor añade que es muy probabłe que los tres primeros animales hayan sido tomados del "dodekaoros" de los signos del Zodiaco antiguo (cfr. Cumont, F.: "Zodiaque", en Darenberg-Saglio: Dictionaire des antiquités y Caquot, A, "Sur les quatre bêtes de Danjel", Semitica, 5, 1955, p. $6 \mathrm{ss}$ ), mientras que la cuarta bestia es, indudablemente, una creación judía.

2x Para mayores detalles sobre la interpretación exegética de estas visiones puede consultarse, entre muchas obras especializadas, la ya citada edición de M.Garcla Cordero y los profesores de Salamanca: La Biblia comentada, III: Libros proféticos, Madrid, B.A.C., 1967, espec. págs. 1001-32.

Imagen y representación de los otros Hispania Sacra 48 (1996) 
Alejandro, el conquistador-relámpago. El profeta ha elegido el leopardo para representar la agilidad inenarrable de este coloso de Ia conquista. Las cuatro cabezas de esta excepcional bestia parece ser los cuatro sucesores de Alejandro, o diádokos, que se repartieron el imperio del inmortal macedonio"29. El cuarto reino y la cuarta bestia son, sin lugar a dudas, los más difíciles de interpretar y los que han dado lugar a la mayoría de los problemas. La descripción de la bestia -exótica y que no representa a ningún animal concreto- creó dificultades al propio Daniel al no encontrar con qué compararla, además de definirla como "más terrible y espantosa" (VII-7).

Muchos pensadores del mundo clásico y exégetas antiguos y actuales, pese a las dificultades, no vacilan en identificarla con los reinos epigonales sucesores de Alejandro ${ }^{30}$. Sostienen que en XI, 4-45 encontramos la clave para interpretar las alianzas humanas que simbolizan el hierro y el barro que caracterizan al cuarto reino (VII-43). En ese capítulo se habla de las alianzas matrimoniales que entablarán los seleúcidas de Siria y los Lágidas de Egipto para unirse en la posesión de Palestina. Sin embargo, las tentativas fueron inútiles, y las dos grandes familias no pudieron fundirse, como no se pegan el hierro y el barro (VII-41). Por otra parte, en VII-7 se habla de una bestia feroz "con grandes dientes de hierro" que es suplantada por el "reino de los santos. Ya san Jerónimo confiesa que el "pequeño cuerno" de la cuarta bestia del cap. VII y el "hombre despreciable" del XI, 21 designan a Antíoco IV Epífanes, perseguidor de los judíos de la época macabea" 31 . Finalmente, en el texto del capítulo VII se hace referencia a un quinto reino (el reino de los santos) que derrumba al coloso de "pies de hierro y arcilla" y que es "el reino que no será jamás destruido" (VII-44), reino que a su vez se prestó para muchas -y muy diferentes- interpretaciones vinculadas a la temática que estamos analizando.

Bien señalan los exégetas que "en el contexto de la profecía de Daniel se trata del anuncio de un futuro señorio e imperio, reconocido por todos los pueblos y naciones, y ese dominio será eterno...; expresiones que en la literatura bíblica del Antiguo Testamento se aplican siempre a la edad definitiva del mesianismo"32.

$$
* * *
$$

29 Profesores de Salamanca: op. cit., p. 1028.

3. El primero que efectuó esta interpretación, señalando que el cuarto reino se refería a los seIéucidas parece haber sido Porfirio en su "Contra los cristianos", según MAZZARjno (op. cit., p. 39.

31 Idem, p. 1002.

32 lbidem, p. 1031. 
Retomando la tesis de la sucesión de los imperios a la historia asiriobabilónica y medopersa originaria ${ }^{33}$, que en los primeros tiempos fue separada en meda y persa como segundo y tercero respectivamente, se agregó el imperio macedónico de Alejandro Magno, al considerarse a sí mismos como los sucesores del imperio persa. Es muy probable que este agregado "se deba a Demetrius de Phalerón, observador de la mutación de la materia humana en ocasión de la caída de Persia por Macedonia"34.

Cabe recordar que el mundo helenístico del siglo II a. C. se caracterizó por la confluencia de una serie de creencias y religiones ${ }^{35}$ que conformaron un verdadero sincretismo que aún no ha sido suficientemente estudiado y que condicionó gran parte de la cultura posterior. Entre las múltiples manifestaciones de éste -en el campo de nuestro interés inmediato- parece importante mencionar que en el templo de Hiera-Komé, construído por Ciro a cincuenta millas de Pérgamo, los colonos persas (magusaioi) y sus sacerdotes de Artemisa, proclamaron "la inmediatá aparición de la quinta monarquía, profetizando en su excitación la expulsión del odiado Antíoco III" por los romanos (odio que compartían con los judíos de la diáspora). Según Swain "este templo fue el centro por el cual la profecía se desparramó por el Oeste"36.

El contacto de la naciente potencia de Roma con el mundo helenístico, tras las victorias de Cinoscéfalos (199) y Pidna (168) produjeron temor y oposición a la surgente Roma y luego admiración y preocupación. La generación de finales del siglo III y principios del II vivió embelesada por la cultura griega con que se contactara, a la vez que los helenos trasladados a Roma, tal el caso de Polibido y Posidonio se admiraron del prestigio y grandeza de Roma y se dedicaron a investigar sus causas. Tal el origen de la Historia Universal de Polibio y de las investigaciones históricas de Fabius Pictor y del poeta Ennio. Este -en el tema que nos ocupa- llegó a conectar el final del imperio asirio de

33 Es interesante hacer nolar la casi inexistencia en estas listas del antiquísimo imperio egipcio, ausencia que solamente parece explicable -después de la importancia que por su parte le confiere Herodoto- (todo el libro II, tras considerarła como la civilización más antigua de ta tierra)- si aceptamos que la teoría tiene un origen babilónico, opuesto a Egipto. Cabe señalar aquí que la trascendencia histórica de Egipto debe mucho a los descubrimientos de Champillión en tiempos de Napoleón Bonaparte y fue casi una moda histórica hasta fines de la dêcada de nuestro siglo en que SAMUEL NOAH KRAMER escribiera que "La historia empieza en Súmer".

34 ALONSO NúNEZ, J.M.: Aemilius Sura, op. cit., p. 114. La referencia está tomada de Polibio (XXIX, 2], 3/6) y éste ha de haber usado a Eforo (V-33, 2), cita que Mengels, entre otros, consideraba interpolada.

35 "En las nuevas ciudades fundadas por las dinastías helenísticas, se encuentran los discípulos de la astrología caldea y del parisismo iraní, los creyentes de la teología siríaca y de la escatología egipcin" (PERETTl, AURELlO: La Sibilla babilonese nella propaganda ellenisfica, Florencia, La Nuova Italia, 1943, p. 8). El autor omite agregar el judaísmo helenizado.

36 SWAIN, J. W.: op. cil., p. 12. 
Nino -primero de la serie- con la fundación de Roma, para de ese modo integrarla al desarrollo de la historia universal ${ }^{37}$.

Pero hacia mitades del siglo esta actitud cambió y los intelectuales tradicionalistas acaudillados por Catón comenzaron una acerba crítica a los griegos, temerosos de los cambios de costumbres e intereses que éstos implicaban. A esta nueva generación parece haber pertenecido el historiador Aemilius Sura -de controvertida existencia- quien habría escrito, hacia el 171 a. C., una historia, De annis populi Romani -que no ha llegado a nuestras manos-, en la que ubicaba a Roma como el quinto? (reino de los santos) y último reino de esta sucesión que estamos analizando ${ }^{38}$. El párrafo de Sura -único que nos ha llegado- ha sido rescatado por Veleyo Patercolo, un contemporáneo de Augusto y Tiberio; al citar en su obra los anales de Aemilius Sura transcribe de éste que: "primero los asirios sometieron a todas las naciones, después hicieron lo mismo Ios medas, después los persas, finalmente los macedonios; y después de dos reyes de origen macedonio, Filipo y Antíoco, obtenida poco después la sumisión de Cartago, el dominio pasó a manos del pueblo romano". Y agrega: "Entre este momento y el comienzo del reino asirio de Nino, que fue el primero que tuvo la supremacía universal, transcurrieron mil novecientos noventa y cinco años"39. "En este camino una teoría oriental y griega se transformó en doctrina de glorificación de la expansión del poder imperial de Roma" 40 . La posible interpretación de Sura, coincidente con los "oráculos" de Hiera-Komé, asumía las tesis de Polibio y sus contemporáneos (del "círculo de los Escipiones") destinada a engrandecer y justificar el papel de Roma como nueva potencia del Mare Nostrum.

Un siglo más tarde la expansión romana había cambiado la admiración por el odio y los pensadores del Oriente solo deseaban, tras las sangrientas campañas bélicas vinculadas con Mitrídates y la caída de Siria en manos de Pompeyo, una "venganza oriental". Así no debe llamarnos la atención que en la

37 Esta curiosa -y forzada- tesis reaparece en San Agustín en La ciudad de Dins (XVIII-27, probablemente basándose en Vartón.

38 "Los hechos que narra Sura -según Swain ( $o p$. cit ), referidos a la tercera guerra de Macedonia (17I) señalan la posibilidad que esta idea de las cinco monarquías haya nacido en Roma por obra de los embajacores de Judas Macabeo en 162 (I Macabees VIII), aunque estos embajadores no hayan identificado la quinta monarquía con Roma" (p. 4, nota 9); tesis que por otra parte no está muy distante de una simple conjetura. Por otra parte las conclusiones a que arriba Swain, sobre el papel que le cabe a Sura -cuya existencia ha sido motivo de muchas dudas- han sido criticadas -en mi opinion de manera hipercrítica- por D. MENDELS (The five enpires..., p. 334) al considerar escasa documentación la glosa de Veleyo, la vaga sentencia de Ennio y la conjetura de una posibje interpolación de Polibio.

39 Veleyo Patercolo: Historia, I- 6, 6 .

4t) ALONSO NÚNEEZ, J.M., op. cit., p. 115. 
segunda mitad del siglo I a. C. arreciasen gran cantidad de profecias antirromanas, que modificaban el papel asignado a la" nueva potencia" durante el siglo anterior.

A este grupo -que muestra nítidamente cómo se mezclaban la tradición judía y la iránica- pertenecen los oráculos sibilinos ${ }^{41}$, directamente vinculados al ambiente mesiánico zelote de la Palestina.

Puede resultar de interés recordar que "en la tradición griega, aceptada por los romanos no más tarde del cuarto siglo a $\mathrm{C}$. y por los hebreos no más tarde del siglo II a. C. las Sibilas eran antiguas mujeres capaces de predicciones estáticas de desgracias o desastres. La erudición helenísticoromana coincidía que los oráculos sibilinos circulaban antes de la guerra de Troya y que Homero había sabido por los oráculos sibilinos el futuro del descendiente de Eneas. De hecho, todavía la primera mención de una sibila en la literatura griega es un fragmento de Heráclito ${ }^{42}$ que no puede ser muy anterior al $500 \mathrm{C} .{ }^{.43}$. Por otra parte la tradición antigua, recogida por Dionisio de Halicarnoso (IV-62), afirma que los libros sibilinos llegaron a Roma bajo la realeza etrusca, fueron conservados en el templo Capitolino, quemados en el incendio del 83 a. C., reconstruidos por emisarios en las ciudades de la Hélade, la península itálica y el Asia Menor y finalmente expurgados de su antiromanismo por Octaviano Augusto 44 .

"En la compleja versión, muchas veces reelaborada, que nos ha llegado se ha mezclado desordenadamente material de origen pagano, judío y cristiano, de naturaleza histórica, política y religiosa, cuya datación puede establecerse genéricamente en un largo período de tiempo que va del siglo II a. C. hasta el I de nuestra era $^{45}$. Entre ese material nos interesan especialmente los libros $\mathrm{H}$,

41 Gabriella Amiomt ("Gli oracoli sibillini e il motivo del re d'Asia nella lotta contro Roma", en Contributi dell Tstituto di Storia Antica del Sacro Cuore, VIII, Milán, 1982) sostiene que "la presencia de un tema oracular de matriz oriental, anunciando la venida de ил rey vindicador del Asia (existía) ya en el siglo $\vee$ a. C." (p. 24)

42 DIELS, 92.

43 Momigliano, A., Dalla Sibilla pagana... p. 408.

44 Véase: Bloch, RAYMOND: Los prodigios en la Amigïedad clásica, Buenos Aires, Paidos, 1968, espec. p. 115-6, y del mismo autor "La divinitation romaine et les livres sibyllins", Revue de.s Etudes Latines, 1962. Respecto a ta decisión de Augusto nos relata Suetonio que "hizo reunir y quemar más de dos mil volúmenes de predicciones griegas y latinas que circulaban y sólo tenían sospechosa autenticidad. Unicamente conservó los libros sibilinos y en éstos hizo una expurgación, encerrándolos en dos armarios dorados, bajo la estatua de Apolo Palntino" (Augusto, XXXI).

4s SinisCalCo, P., "L idea dell'eternitá e della fine di Roma negli autori cristiani primitivi", Srudi Romani, XXV, 1, enero 1977, p. 5. El tema de la estructura e intercalaciones en la Sibila a través del tiempo, ha sido cuidadosamente investigado por A. Peretti en su ya citada La Sibilla babiIonese nela propaganda ellenistica, Florencia, La Nuova Italia, 1943.

Imagen y representación de los otros

Hispania Sacra 48 (1996) 
IV y V de la llamada "versión judía ${ }^{46}$. El libro III -que reune el más antiguo de los oráculos judíos-, después de una introducción y algunas consideraciones mitológicas, aporta una breve reseña de los reinos universales (fragm. $158 \mathrm{ss}$ ) incorporando en cuarto y último lugar a Roma." Más adelante (175 ss.) se habla también del fin del dominio greco-macedónico por obra de los romanos, del comienzo de un nuevo dominio "blanco y de muchas cabezas, un imperio del mar occidental", que señoreará sobre una gran parte del mundo y hará, temblar a muchos y producirá espanto a todos los reyes y sacará mucho oro y plata de muchas ciudades. Pero vendrá enseguida la hora de su fin, y éste se originá en la prepotencia, impiedad y avidez del nuevo dominio, y será causa de perturbaciones y de guerras sin fin. Después sigue un intermedio donde se habla del pueblo elegido y de la derrota de las potencias mundanas. Lamentaciones sobre ciudades, pueblos y reinos se acumulan sin orden, y después se elevan imprecaciones contra Roma ( $350 \mathrm{ss}$.). El Asia se tomará una terrible venganza de manera repentina sobre Roma"47. El libro III también hace referencia a los sueños de Daniel identificando el cuarto imperio con el de Macedonia ( $388 \mathrm{ss}$.), aunque la cuarta bestia es referida a Roma ${ }^{48}$.

En el libro IV, a su vez, al referirse nuevamente a los imperios mundiales se alude a las raíces de la "venganza oriental", mencionándose "la calamidad inferida al Asia por la soberbia Hélade en tiempos de la guerra de Troya"49.

Finalmente, en el mismo libro IV, se menciona la división de los cuatro imperios en el siguiente orden: Asiria, que "tuvo poder sobre todo el universo"

46 "Los tres libros judíos de los Oráculos sibilinos son, después de ta versión bíblica de los Setenta, el documento más importanse y significativo de la propaganda religiosa y de la fuerza expansiva del judaísmo alejandrino... Otro aspecto interesante de la colección sibilina es que el material apocalíptico se trasmitf́a en gran parte de una generación a otra. Los sibilistas judłos compusieron solo en parte una obra original. En muchos casos de ellos retomaron motivos apocalípticos judíos y paganos, transformaciones, según las circunstancias o los intereses del momento, muchos elementos más antiguos, atentos a las fuentes orientales y a la sibilística griega" (Peretti, A., op. cit., p. 26).

47 PERETT1, A., op cit. p. 27. El mismo autor aclara que la composición de este tercer libro -comúnmente conocido como Sibilina eritrea- y que contiene material pagano intercalado en el "cuerpo" de la Sibila judía, se debe a un judío de Alejandría que escrib́a hacia fines de la revuelta de los Macabeos (140 a. C.). Otros, en cambio, estiran la redacción hasta los tiempos de Sila y Pompeyo en relación con una comisión enviada al Oriente en el 83 a. C. Este tema debe vincularse a las profecías de raíz etrusca vinculadas con el fin de Roma. Para ampliar este aspecto véase: Sordi, Marta: "L'ídea di crisi e di rinnoyamento nella concezione romano-etrusca della storia", A.N.R.W., 1972; BAYET, JEAN: Croyances et rites dans la Rome antique, Paris, Payot, 1971; MAZZARIO, SANTE: El fin del mutndo antiguo, Méjico, U.T.E.H.A., 1961, y HUBAuX, J., Les grandes myther de Rome, París, P.U.F., 1945.

48 DeLCOR, MATHIAS: La prophetie de Daniele (II y VII) dans la litterature apocalyptique julive et chraetienne en reference speciale a I'Empire romain, en Da Romia alla Terza Roma, 1986, p. 12.

49 Аміотт, G., op. cit., p. 24. 
dominando al mundo durante seis generaciones (47 ss.) luego los medas (49 ss.); sucedidos por los persas, "que tuvieron poder supremo sobre todo el mundo" (61 ss.). Cuando la raza de los mortales llegó a la décima generación aparecieron los macedonios (86 ss. $)^{50}$. En algunas versiones parece no quedar duda que el cuarto reino se refiere a los Seléucidas, ya que la redacción oracular es anterior a la expansión romana y la interpretación se modifica en tiempos de Mitrídates, reapareciendo el antiguo tema oriental de la "venganza" contra el usurpador, en este caso, identificada con cuestiones religiosas.

En el ambiente rabínico judío aparecieron otras profecías -a veces identificadas con lo oráculos sibilinos- que tratan la temática que nos ocupa. Entre estos textos, redactados presumiblemente hacia el siglo II a. C. -época de desarrollo del mesianismo motivado por las persecuciones seléucidas- se destacan La Asunción de Moises (30 a. C.), los Salmos de Salomón (año 45). También los difícilmente datables apocalipsis de Baruc (II, XXXIX-3/7) ${ }^{51}$ y Esdrás (IV, XII-11/12) ${ }^{52}$. En ellos reaparece la temática de las cuatro monarquías, que unía a Media y Persia y ubicaba a Roma en cuarto lugar, reservando el quinto (el reino de los santos) para la "restauración judía" o, al menos, la "venganza" del Oriente, en el mismo espíritu de la profecía de Daniel.

La más antigua interpretación surgida en este ambiente y en este conjunto de ideas pertenece al historiador judío Flavio Josefo al referirse a las profecías de Daniel que nos ocupan. En sus Antigüedades judias apunta: "Esta visión escribió Daniel haberla visto cerca de Susa; Dios le indicó el significado. El carnero representaba los reinos de los persas y los medos, los cuernos indicaban el número de sus reyes y el último cuerno señalaba al último rey que superaría a todos en riquezas y gloria. El macho cabrío se refería a un rey de los griegos, que por dos veces se impondría a los persas y así obtendría el dominio y se convertiría en heredero de todo su poderío. El gran cuerno que salía de la frente del macho cabrío indicaba al primer rey; los cuatro significaban, con su orientación hacia los cuatro puntos de la tierra, los sucesores del primer

50 FLUSSER, D., op. cit., p. 15l. Este autor considera que el libro IV fue escrito por un judio hncia el 80 a. C., basánđose en una versión antigua del libro III perteneciente al siglo anterior, ya que en el esquema original no aparecen los Romanos, que fueron agregados como quinto imperio ( 102 ss.) ã̃adiéndose también la "venganza de Așia" ante la ocupación romana (145 ss.).

5I "Por varios indicios se puede presumir que las palabras del Apocalipsis de Baruc hayan sido escritas poco después de la caída de Jerusalén en el 70 de nuestra era" (SINISCALCO, P. L'ídea dell'eternitä..., p. 4).

52 "Es notable a nuestro propósito relevar que la imagen de los cuatro reinos se reencuentra no solamente en la apocalíptica, sino fambién en la literatura rabínica (el Midrash Tehillim Ps, 16,7; el Yalqut Shimeoni comentando el Génesis XV 17, el Targ. Jerush. fragmmentario, en Gén. XV-12. También Tanhuma. Teruma VI, Bereshit Rabb", XCIX, 2; Pirqú de Rabbi Eliézer VIII) "(Síniscalco, P., op. cit., p.5). 
rey después que éste muriera, y el reparto de su dominio entre ellos. Estos reyes, que no eran ni sus hijos ni sus parientes, gobernarían el mundo durante muchos años. De entre los últimos saldría un rey que atacaría a los judíos y a sus leyes, destruiría su forma de gobierno, saquearía el Templo y prohibiría que se celebraran sacrificios durante tres años. $\mathrm{Y}$ en realidad así aconteció, pues nuestro pueblo sufrió tales cosas bajo Antíoco Epífanes, según lo vio Daniel y lo puso por escrito muchos años antes. También escribió Daniel sobre el imperio de los romanos, que sería sumamente dilatado" (X-11).

Este tema de las cuatro monarquías y la "venganza oriental" tampoco es ajeno al resto del mundo oriental. Así, por ejemplo, la profecía conocida como el oráculo de Hystaspes ${ }^{53}$, debida presumiblemente a un oriental helenizado, un mazdeo o a un griego oriental muy embebido en las doctrinas de los magos de Zoroastro ${ }^{54}$, retoma el tema de "un rey oriental vindicador" convertido en la Persia del siglo $\mathrm{V}$ a. $\mathrm{C}$., por la tradición mazdea, en un monarca guerrero ${ }^{55}$.

Fue un historiador de origen galo de la época augustea llamado Pompeyo Trogo -al que conocemos gracias al Epitome de Justino del siglo II-quien en su Historice Philippicae -en cuarenta y cuatro libros- "oficializó" la teoría de las cuatro monarquías con Roma incorporada en cuarto lugar -al modo oriental- como "potencia mundial". Su narración comienza con un análisis de la historia de Asiria, para dedicar luego una parte extensa a Persia -ya que Media es solo una transición entre asirios y persas--. Después Trogo incorpora a Filipo de Macedonia y prosigue unitariamente el relato hasta la llegada de los romanos $^{56}$.

$\$ 3$ Este oráculo nos es conocido por las referencias de Justino en su "Apología", redactada en el siglo II, donde señala que "la Sibila e Histaspes dijeron que setían consumidas por el fuego todas las cosas que están sujetas a corrupcion" $(l, 20)$ y en otro parrafo advicrtc que "ha sido decrctada la muerte contra aquellos que lean los libros de Histaspes, de la Sibila o de los profetas" (I-44). "La expresión de Horacio (especialmente en el épodo VII) sugiere el origen pártico-persa del oráculo de venganza contra Roma; y además es muy probable que el oráculo de Hystaspes, considerado por Lactancio "antiquissimus Medorum rex", circulase ya en el mundo romano en el siglo I a. C. El fragmento de Antistenes (de Rodas) con la mención de un rey de Asia que viene a sujetar a Roma e Italia revela que en el origen de este oráculo era muy antiguo" (Amiotti, G. op. cit., p. 23).

s4 Cumont, F. La fin du monde... p.64.

s5 Este mismo tema orientalista "repetido y readaptado a las variadas situaciones históricas fue empleado en Ia lucha contra Roma primero por Antíoco III, después por Mitrídates, por Cleopatra, por los partos y los persas." (AMIOTTl, G., op. cit. P. 26).

56 Véase: Pavan, Massimillano: "Le profezie di Daniele e il destino di Roma negli scrittori latini cristiani dopo Constantino", en Da Roma alla Terza Roma, 1986, p. 293, nota 8. J. M. Alonso NúN̄EZ (op. cit.) plantea la posibilidad que Trogo haya consultado a Ctesias aunque sea de segunda mano, através de Detrius de Phalerón, considerado como el primer griego que emplea esta teoría; sin perjuicio que este autor reconoce el precedente de Herodoto (op. cit., p. 112, nota 12). FLUSSER, a SU vez, asegura "no encontrar en la composición del trabajo el esquema de los cuatro imperios" (op. cit., p. 158 , nota 39 ). 
Pero la Roma considerada predestinada para cumplir un papel de "pueblo elegido" en la historia de la humanidad como lo esbozara la generación de Polibio, influida por las sucesivas victorias que le otorgaban el dominio del Mare Nostrum y motivada por los oráculos orientales antiromanos modificó la conformación tradicional de la teoría de las cuatro monarquías, convirtiendo a Roma no en la cuarta sino en la quinta (la destinada a la eternidad), tema que D. Mendels identifica como el topos de "cuatro más uno"57.

Esta tesis aparece esbrozada, como ya vimos, en Aemilius Sura y adquiere consistencia definitiva en la historiografía romana, presumiblemente en el siglo I de nuestra era, en el griego Dionisio de Halicarnaso o más precisamente en Tácito. Este, en sus Historias afirma que mientras el imperio de Oriente estuvo en poder de los asirios, medos y persas fue este pueblo el más menospreciado entre los que vivian en servidumbre. Después, prevaleciendo los macedonios, el rey Antíoco..." 58 para pasar, finalmente, a ocuparse de los romanos. Casi paralelamente en.el mismo siglo I, el griego Dionisio de Halicarnaso escribe en la introducción a sus Antigüedades rontanas que "el imperio de los asirios, que era antiguo y se remontaba a los tiempos míticos, solo dominó una pequeña parte de Asia. El imperio de los medas, después de aniquilar, no prevaleció mucho tiempo, sino que fue destruido a la cuarta generación. Los persas, una vez que vencieron a los medas, se apoderaron finalmente de casi toda Asia; pero cuando atacaron también a los pueblos de Europa, no sometieron a muchos y no permanecieron en el poder mucho más de doscientos años. El imperio Macedónico, que destruyó la fuerza de los persas y cuyos dominios superaron en extensión a todos los anteriores, tampoco floreció durante mucho tiempo, sino que después de la muerte de Alejandro empezó a decaer..." 59 .

Y el mismo "topos" reaparece, en el siglo siguiente, en Apiano, quien al redactar su historia romana señala en el prólogo: "De otro lado, la duración de los imperios asirios, meda y persa, los tres imperios mayores hasta Alejandro el hijo de Filipo, considerada en conjunto, no llegaría a los novecientos años, tope al que han llegado los romanos en la época actual"60.

57 "El autor rescata el origen en el helenismo antiguo (siglo I a. C.) e insertado tempranamente en el esquema del cuarto oráculo. $Y$ concluye que el topos de los cuatro imperios del Este y Roma como quinto imperio surge en la última mitad del primer siglo a. C. en la historia griega y romana, después es usada indistintamente en (formas similares) por aliados y enemigos de Roma, en diferentes interpretaciones, todas sobre el imperio" (MENDEL, D., op. cir., p. 337).

s\& TÁCITO, Historia.r, V-8/9.

59 Dionisio, Anigüledades romanas, [, 2, 2-4.

60 APIANO, Historia romana, prólogo, 9. 
A fines de ese mismo siglo el topos no es ajeno a un retor como Elio Arístides, quien en su Discurso Panatenaico (234) nos muestra que conoce la lista ordenada de los cinco imperios, tema que reaparece en su más conocido Elogio a Roma".

Todos estos textos nos señalan que el "reino feliz" ya no era considerado -en el mundo pragmático romano- una esperanza para el futuro (mesianismo judío) sino que se daba en el presente ${ }^{61}$ y para muchos de sus contemporáneos el imperio romano era -a partir de Augusto- la instauración de una nueva edad (saeculum) de oro.

Y el topos persiste en la literatura pagana de Roma hasta finales del mundo antiguo ya que aún el siglo $\mathrm{V}$ de nuestra era el poeta Claudiano, en su De consulatu Stilichonis, escribía: "No tenemos límites para el imperio de Roma... Así los medas despojaron a los asirios del imperio, y los persas a los medas. Macedonia suplantó a Persia y fue por sí mismo a Roma"62 .

$$
\text { *** } *
$$

Pero la temática que nos ocupa no se limitó a la literatura persa, judía o grecoromana sino que -como era obvio- sufrió una importante y curiosa transformación por obra del cristianismo, en el contexto de los interrogantes que la Roma augustea-eterna planteó a los primeros pensadores de la "buena nueva"63. La cuestión surgió fundamentalmente al analizar los teólogos de los primeros siglos del cristianismo las profecías de Daniel y por influencia judía asumió un notable tinte apocalíptico; enfoque que, por otra parte, se vio acentuado en los dos primeros siglos tanto por las persecuciones de Nerón y sus seguidores como por la concepción apocalíptica de la primera generación de cristianismo ${ }^{64}$, que se nota claramente en la redacción del Apocalipsis de san Juan.

Uno de los puntos que más llamó la atención de los exégetas de la época fue el llamado Katejón u "obstaculo" paulino, incorporado por el apóstol Pablo de Tarso en su segunda carta a los tesalonicenses, a quienes escribe con respecto a los "últimos días": "Vosotros sabéis que es lo que ahora lo retiene, para que se manifieste en su momento oportuno. Porque el misterio de la impiedad ya está actuando. Tan sólo con que sea quitado de en medio el que

61 Cfr. la Eneida de Virgilio o el recien citado Elogio a Roma de Arístides, que son más que elocuentes para este tema, cuyo anúlisis más detallado nos alejaría del objetivo de esta breve ponencia.

62 cit. SWAIN, J.W., op. cit., p. 14

63 Véase nuestro: "Encuentro del cristianismo con la cultura clásica", Polis: Revisia de ideas y formas políticas de la antigüedad clásica, 4 (1992), p. 157-71.

a Véase, por ejemplo, GARCÍA, RuBén, La Jglesia pueblo del espíritu. Las primeras comunidades cristianas en los Hechos y Apocalipsis, Don Bosco-ISPA, 1983. 
ahora lo retiene, entonces se manifestará el Impió"(II Tes.II-6/8). Este obstáculo fue rápidamente identificado con Roma, favorecido porque Pablo no lo hubiera reconocido expresamente.

"Y es en los primeros años del siglo III cuando aparece por primera vez una explicación destinada a conocer una fortuna duradera y una profunda significación política: relaciona con Daniel la perícopa de II Tasalonicenses e identifica no solamente Roma con el cuarto reino de Daniel sino también con el obstáculo paulino... [Esta] identificación [...] constituye un problema muy ardiente pues este reino y este obstáculo podían ser considerados como negativos y que retardarían la parusía, o como positivo, en el sentido que tendría los terribles cataclismos del fin del mundo" (II Tes. II-1/8: Mateo XXIV$4 / 22)^{65}$.

En este mismo espíritu y ambiente apocalíptico escribió, en el siglo III, Lactancio sus Instituciones Divinas, en las que destina buena parte a la temática del "fin de los tiempos", además de hacer referencia -como ya vimos-al oráculo de Hystaspes que obviamente no le fue desconocido. En la obra citada relata: "El motivo de esta devastación será éste: el nombre de Roma, que ahora domina sobre el mundo -horroriza decirlo, pero lo diré porque así va a suceder-, será arrancado de la tierra, el imperio volverá al Ásia, y de nuevo el oriente dominará y el occidente será esclavo. $\mathrm{Y}$ a nadie debe extrañar que un imperio que tiene tan sólidos cimientos, que ha crecido durante tanto tiempo gracias a tantos y tan extraordinarios hombres y que finalmente se ha consolidado con tantos recursos, termine algún día en la ruina. $Y$ es que no hay nada hecho por fuerzas humanas que no pueda ser destruido igualmente por fuerzas humanas, ya que las obras de los mortales son mortales. Así sucedió que otros imperios, a pesar de haber florecido largo tiempo, desaparecieron. Efectivamente, se nos ha trasmitido que los egipcios, los persas, los griegos y los asirios gobernaron sobre la tierra; tras la destrucción de todos ellos, el imperio llegó a los romanos; y éstos, en la misma medida en que superan a todos los demás reinos en magnitud, en esa misma medida será mucho mayor su caída, ya que lo que está más alto que lo demás cae con más peso"66.

A partir de estas nuevas interpretaciones "el imperio ciertamente no es eterno como lo creían los paganos, pero durará hasta el fin del mundo como lo han dicho Daniel y Pablo"67.

El primer autor cristiano del que tenemos noticia de que haya analizado las profecías de Daniel es Ireneo de Lyón, en el siglo II, quien en su Adversus

65 PASChOUD, F., Roma aeterna, Inst. Suisse de Rome, 1969, p. 176 y $171-2$.

6 LACTANClO, Instiniciones divinas, VII-15, 19.

67) Idem, p. 186

Imagen y representación de los otros

Hispania Sacra 48 (1996) 
haereses no vacila en inclinarse por la interpretación de Roma como cuarta bestia ${ }^{68}$, pero las primeras investigaciones importantes sobre el tema pertenecen a Hipólito de Roma, quien en el siglo III se dedicó específicamente a estudiar el Libro de Daniel y redactó un importante trabajo sobre el Anticristo.

Al comentar la visión del Libro II expone que la estatua que se apareciera a Nabuconodosor contenía figurativamente el imperio del mundo; en época en que gobernaban los babilonios, que eran la cabeza de oro de la estatua. Después fueron señores los persas durante 245 años, lo que prueba que eran de plata y la dominación pasó entonces por 300 años a los griegos, desde Alejandro de Macedonia, y éstos eran de bronce. A éstos sucedieron los romanos, que eran las piernas de hierro de la estatua, pues eran fuertes como el hierro. Después vienen los dedos de los pies -de arcilla mezclada- que representan las democracias futuras que se separarán las unas de las otras como lo están los pies de la estatua. Hipólito aclara que el imperio romano, a diferencia de los anteriores, no estaba formado por un. solo pueblo sino "de todas las lenguas y de cada raza de hombres reunida por si" y prepara una fuerza militar para hacer la guerra, y son todos aquellos que son llamados Romanos y que no provengan todos de una sola tierra". El mismo Hipólito concluye que el Señor nació en el cuatrigésimo año del reinado de Augusto, cuando la fortuna de los romanos estaba en su apogeo, y por medio de sus apóstoles ha llamado hacia sí a todos los pueblos y todas las lenguas para convertirlos en pueblo de cristianos, que llevan escrito en su corazón el mismo nuevo nombre ${ }^{69}$.

Como bien aclara Simonetti " la interpretación de la estatua es simple y lineal, pero altera profundamente el sentido original de las palabras de Daniel para adaptarlas a la interpretación paralela de la visión de la cuarta bestia actualizada según la interpretación del Apocalipsis (13 y 17). Porque sobre esta base la cuarta bestia se convierte en el imperio romano, paralelamente también en la visión de la estatua las piernas de hierro, originariamente símbolo del imperio macedónico, pasan a significar el imperio romano y en consecuencia tambiên el sentido de la parte precedente y siguiente de la visión está modificado"70.

En el siglo IV el tema no resulta ajeno a Eusebio de Cesarea, el historiador griego autor de una "verdadera teología política" para el emperador Constantino. La teoría de los cuatro imperios curiosamente no aparece en la Crónica y ni siquiera en su célebre Historia eclesiástica, pero la encontramos en la $D e$ -

68 SimonetTI, Manlio, "L'esegesi patristica di Daniele 2 e 7 nel II e III sccolo", en Da Roma alla Terza Roma, 1986, p. 40.

69 Véase: DeLCOR, M., La prophetic de Daniele... cit., y Simonetti, Manlio, L'esegesi patristica... cit.; ambas en Da Roma alla Terza Roma, 1986.

70. SIMONETT, MANLIO, op.cit., p. 42. 
monstratio evangelica, donde al analizar a Daniel identifica sus cuatro reinos con Asiria, Persia, Macedonia y Roma ${ }^{71}$.

Pero el verdadero continuador de la corriente de ideas de Hipólito es san Jerónimo -cuya biografía histórico-política basada en su importante e interesante correspondencia aún está pendiente-, a quien también se debe un $\mathrm{Co}$ mentarioda Daniel.

Este, de manera similar a Hipólito, reúne Babilonia y Asiria bajo la denominación de esta última y agrupa en una unidad -como lo ha aceptado la historiografía universal posterior- los reinos de Media y Persia. El texto de Jerónimo, referido a Daniel II, es el siguiente: "Tú eres la cabeza de oro". Y con esto muestra que el primer reino, el de los babilonios, se compara al oro preciosísimo (II-39). Y depués de tí surgirá otro reino, inferior al tuyo, de plata. $O$ sea el reino de medas y persas, comparado a la plata, inferior al anterior, superior al siguiente. Y en un tercer reino de bronce, dominará sobre toda la tierra. Se refiere a Alejandro y el reino de Macedonia y de los sucesores de Alejandro; cuyo reino es justamente llamado de bronce, ya que entre todos los metales el bronce es el más resonante y da un sonido más claro y su voz se difunde en duración y largueza, esto es para indicar no solo la fama y la potencia de aquel reino, sino sobre todo la elocuencia de la lengua griega (II-40), $\mathrm{Y}$ un cuarto reino será como el hierro: del mismo modo que el hierro quiebra y tritura todo, así éste quebrará y destruirá tada aquella. El cuarto reino, puesto que se refiere a los romanos, es de hierro, que quiebra y tritura todo. Pero que en este tiempo se comprueba de manera clarísima. Como en efecto al principio nadie fué más fuerte y más inflexible que el imperio romano, así ahora nadie es más debil, ya que en las guerras civiles y contra diversa gente necesitamos la ayuda de otros pueblos bárbaros. Al final de todos estos reinos de oro, de plata, de bronce, y de hierro, una piedra fue desprendida, sin que mano alguna haya intervenido (II-45), o sea el Señor y Salvador, sin unión ni semen humano, nació del útero virginal y, destruidos todos los reinos, ha surgido montaña grande y ha rellenado la tierra toda"72.

Finalmente, ya avanzado el siglo $V$, el tema reaparece en el hispano Paulo Orosio, cuya Historia contra paganos se convirtió en el modelo de todas las crónicas medievales, en cuanto se refiere a la historia universal.

"SWAJN, J. W., op. cit., p. 19 Este nos advierte que "la sustitución de Asiria por la bíblica Caldea y la omisión de los Medas en Eusebio (y en Hipólito) es muy significativa, porque indica la influencia de los escritores paganos acerca de las cuatro monarq̨iśas.

72 Cit. SintSAlCO, PAOLO, Mito e storia tra paganesimo e cristianesmo, Turín, SEl, 1976, p. 120-1.

1magen y representación de los otros Hispania Sacra 48 (1996) 
Orosio, en primer lugar, cumple un destacado papel en el proceso de asimilación de la cultura clásica -especialmente Roma-73 al "oficializar", aún forzando la realidad histórica, la tesis de la identificación de Augusto con el nacimiento de $\mathrm{Cristo}^{74}$; pero ahora nos interesa básicamente su actitud frente a la teoría de las cuatro monarquías. Sobre el tema escribe en la obra citada: "Al principio del segundo libro, al describir con nuestra pluma el período de la historia de Roma, señalábamos muchas coincidencias entre Babilonia, en otros tiempos, reina de los pueblos asirios y entre Roma igualmente ahora dominante entre las naciones; dijimos que aquél fue el primer imperio, que éste fue el último, que aquél fue descendiendo poco a poco, así como éste fue creciendo claramente; que desapareció el último rey de aquel, cuando surgió el primer rey de éste; que después, invadida y tomada aquella por Ciro, vino a caer en la muerte, cuando ésta levantandose segura de sí misma, después de expulsar a los reyes comenzó a regirse por libre determinación, y sobre todo que, en el preciso momento en que Roma recobra su libertad, fue cuando el pueblo judío, que era esclavo de los reyes de Babilonia, recobra la libertad, volvió a la santa ciudad de Jerusalén y reedificó el templo del Señor como estaba predicho por los profetas. También hemos dicho que mediaron entre el Imperio Babilónico, que estaba situado al Oriente y el Romano, que surgieron en el Occidente, se nutrió con la herencia oriental, surgieron el Imperio Macedónio y el Africano, o sea, aunque por breve tiempo, ejercieron la tutela y gobierno de la parte meridional y septentrional" (VII-1/7).

Y ya anteriormente, como cita en el párrafo precedente, Orosio se había ocupado fundamentalmente en remarcar la coincidencia entre la caída de Babilonia y el surgimiento de Roma, limitando el papel de persas y cartagineses a simples intermediarios en la translatio imperii en una línea de razonamiento parecida a la que varios siglos antes había empleado el romano Ennio al identificar la caída de Asiria con la fundación de Roma. Sobre este tema escribió: "Ahora bien, si el poder viene de Dios, cuánto más los reinos, de donde nacen los demás poderes; y si los distintos reinos, cuánto más aquellos reinos mayores, a los cuales el poder de Ios demás reinos está sujeto, como fue al principio el de Babilonia, después el de Macedonia, más tarde el Africano y al fin el Romano, que dura hasta nuestros días; y con la misma ordenación inefable, como cuatro son las partes del mundo, así hay cuatro reinos que han sobrevivido en distintos medios: el Imperio Babilónico en Oriente; en el Me-

73 Véase nuestro "La cristianización del mito de Roma en Paulo Orosio", Revista de la Universidad Nacional de la Patagonia, I (1987).

74 La tesis puede encontrarse en su obra (Vl-20, 1-3), aunque ya tiene antecedentes en Orígenes, Hipólito, Melitón de Sardes y Eusebio de Cesarea (Hist. ecles. 1-2, 23).

Imagen y representación de los otros Hispania Sacra 48 (1996) 
diodía, el Cartaginés; en el norte, el Macedonio y en el Occidente el Romano" (II-1, 4/5).

Así, para Orosio la historia antes de Cristo se reduce a esto: Roma recoge la herencia de Babilonia y, a través de cruentos enfrentamientos con los imperios intermedios (macedonio y cartaginés) consigue unificar todo el poder en una sola persona, Augusto, cuya época, con el nacimiento de Cristo, marca una divisoria clara"75.

La teoría de los cuatro imperios también tuvo algunos continuadores en el Imperio bizantino, siguiendo las líneas esbozadas por Eusebio de Cesarea. Tal el caso de Cosme Indicopleutense (siglo VI), quien en el segundo libro de su Topografia hace mención a los cuatro reinos que concluyen con Alejandro de Macedonia, pero el "reino de la eternidad", originado con el nacimiento de Cristo, bajo el reinado de Augusto es el Imperium Romanum, cuya continuación legítima era Bizancio, aportando así una justificación teológica al mismo. Basilio de Neopatra, en pleno siglo X, todavía comenta el libro de Daniel en la versión tradicional cristiana de Roma como quinto imperio y aún Juan Malalas, el cronista más importante y popular del Imperio bizantino, ya en el siglo V, en su Chronicon Pascale utiliza la atribución tradicional de los metales referidos a babilonios, persas, macedonios y romanos, entendiendo por éstos a los anteriores al surgimiento del cristianismo ${ }^{76}$ y de esta manera legitima la teoría sucesora para las posteriores obras de historia universal, de raíz bizantina, como lo había efectuado Orosio, para la latina.

Este mismo esquema "cuaternario" de los imperios pasó a través de algunos historiadores grecorromanos ya citados y fundamentalmente por medio de la obra de Paulo Orosio - el manual ortodoxo casi obligado para la historia en el mundo medieval- a Otto de Freisinga ${ }^{77}$ y, por medio de éste, fue el sustrato de las referencias a la historia universal que, conjuntamente con el esquema bíblico de la "historia de las salvación", usaron los cronistas medievales. El topos siguió vigente a comienzos de la Modernidad pudiendo encontrarlo en Melanchton y en Sleidan, hasta que Jean Bodin, en 1566, en el capítulo VII de su Methodus ad facilem historiarum cognitionem echó por tierra esta concep-

7. SÁNCHEZ SALOR, EUSTAQU1, en la introducción a las Historias de Orosio, Madrid, Gredos, 1982, t.l., p. 38.

76 PODSKAisKy, Gerhard, “La profezia de Daniele (cc 2 e 7) negli scrittori dell Impero Romano d'Oriente", en Da Roma alla terza Roma, 1986, p. 311 ss.

7 Cfr. M.G.H, XX, 116-301.

Imagen y representación de los otros Hispania Sacra 48 (1996) 
ción "teológica" de la historia universal, que parecía no adecuarse ya a los inicios racionalistas del mundo moderno ${ }^{78}$.

De todas maneras la idea no estaba definitivamente muerta, y Bossuet, en pleno XVII, al escribir su Discurso de historia universal para el futuro Luis XIV, aunque construya una historia basada en la versión salvífica del pueblo judío elegido, no abandona definitivamente este orden de sucesión y lo emplea en la tercera parte al referirse a los imperios. Más aún, hoy son pocos los historiadores que al acometer la ímproba tarea de redactar una "historia universal" no emplean globalmente, con excepción del caso de Egipto ya citado, el orden sucesorio de Babilonia-Asiria, Persia, Alejandro Magno y Roma, convertido hasta hoy en el matriz estructural de nuestra historia occidental, como lo esbozaran hace tantos siglos los historiadores greco-latinos y -por qué noel profeta Daniel.

Así podemos observar cómo profecía, historia y política aparecen unidas, se entrecruzan y marcan a fuego una constante historiográfica que aún hoy conserva vigencia, aunque muy pocos sepan vincularla con el profeta Daniel.

${ }_{7 B}$ Véase algunas referencins modernas en Gasco La calle, Fernando, "La teoría de los cuatro imperios. Reiteración y adaptación ideológica", $H A B I S, 12,1978$, espec. p. $\$ 80$. 